\title{
Contribuições teóricas da abordagem histórico-cultural para educandos em situação de inclusão
}

Dorcely Isabel Bellanda Garcia ${ }^{1}$

\begin{abstract}
Resumo
Esta pesquisa de cunho qualitativo, desenvolvida mediante estudos teóricos, tem como objetivo discutir, refletir e demonstrar as contribuições da Teoria Histórico-Cultural (THC) para a Educação Especial na contemporaneidade, como possibilidade de atuação com alunos com deficiência no contexto escolar inclusivo. Segundo a THC, a aprendizagem no âmbito escolar provoca processos interiores de desenvolvimento. Nesse sentido, a análise dos estudos indica que, para Vigotski, caminhos indiretos e alternativos, criados pela cultura, devem ser possibilitados aos educandos com deficiências quando os caminhos naturais estão interrompidos. Assim, o acesso e a permanência na escola devem ser possíveis a todos, já que a aprendizagem e o desenvolvimento ultrapassam os limites biológicos. Palavras-chave: Educação Especial; Teoria Histórico-Cultural; Alunos com Deficiência; Contexto Escolar Inclusivo.
\end{abstract}

Theoretical contributions from the historical and cultural approach for students in including conditions

\section{Abstract}

Current theory-based quantitative research discusses, analyzes and demonstrates the contributions of the Historical and Cultural Theory (HCT) for Special Education for application in students with deficiency within comprehensive schooling context. According to HCT, learning within a school milieu causes internal development processes. Several research works has shown that Vygotsky's central theme insists that indirect and alternative pathways, elaborated by culture, should be made possible to students with deficiency when the natural ones are disrupted. Access and permanence in school should be comprehensive since learning and development go beyond biological limits.

Keywords: Special Education; Historical and Cultural Theory; Students with Deficiency; Inclusive School Context.

\section{Introdução}

Neste artigo, referimo-nos às contribuições teóricas da Teoria Histórico-Cultural (THC) para educandos com deficiência em situação de inclusão e demais alunos no contexto escolar inclusivo ${ }^{2}$. Consideramos os estudos de autores representantes da THC importantes devido às considerações e ao valor que atribuem às relações sociais e às interações entre seus pares, em especial quando se trata da educação de pessoas com deficiência. Ainda que os estudos de Vigotski (1997) tenham sido realizados nas décadas de 1920 e de 1930, trazem-nos contribuições valiosas para a educação inclusiva.

\footnotetext{
${ }^{1}$ Universidade Estadual do Paraná/UNESPAR, Campus Paranavaí, dorcelygarcia@hotmail.com

2 Este texto é fruto da tese da autora.
} 
Os objetivos desta pesquisa teórica e qualitativa são discutir, refletir e desvelar como a THC, mesmo atualmente, traz contribuições teóricas importantes para o trabalho com alunos com e sem deficiência no contexto escolar inclusivo; demonstrar que o processo de desenvolvimento do psiquismo humano depende de uma mediação do professor que possibilite este desenvolvimento, bem como contribui para a convivência com seus pares; defender a boa escola para todos, com a valorização das diferentes ciências, pois se espera a contribuição de subsídios que ultrapassam os limites biológicos.

Ao longo deste texto, discutimos algumas indagações, como as seguintes: a inserção do indivíduo na cultura possibilita seu aprendizado e seu desenvolvimento? De qual inserção social e de qual aprendizado estamos falando? Quais recursos são necessários para um trabalho pedagógico que prima pelo conhecimento e que possibilita o processo de humanização? É possível a escola do conhecimento em diferentes instâncias? Qual é o desafio para materializála? Essa possibilidade é viável nos contextos social e escolar em que vivemos, ou seja, em um mundo globalizado e sob os ditames do capital? Todas as discussões são realizadas com base nos principais representantes da THC. Buscamos ainda, em estudos de Vigotski sobre defectologia e em outros estudos da área, subsídios teóricos para o trabalho com crianças em situação de inclusão, sempre com o intuito de encontrar encaminhamentos e ações que favoreçam a passagem do estado de hominização para o estado de humanização.

Trata-se de uma reflexão teórica que relaciona os conceitos de Vigotski $(1997 ; 2001 ;$ 2011) e de seus colaboradores e de pesquisadores de seu grupo, como Leontiev (2004) e Luria (1998; 2001), com pesquisas de autores contemporâneos, como Barroco (2012) e Góes (2002). Em outras palavras, discorremos sobre deficiência, sobre compensação e sobre defectologia, conceitos relacionados às propostas atuais de Educação Especial (EE) e da política Educacional Inclusiva, que, inclusive, norteavam as propostas educacionais daquele momento histórico, e trazemos as reflexões de pesquisadores atuais sobre essas temáticas.

Vigotski (1997) define a defectologia como o ramo do conhecimento que versa sobre os aspectos do desenvolvimento qualitativo das crianças denominadas, na época, "crianças anormais". O objeto de estudo da defectologia acerca da diversidade humana realizado por este autor, sem dúvida, trouxe-nos um olhar diferenciado em relação ao público-alvo da EE.

O termo defectologia foi mantido na presente tradução por corresponder à terminologia 
utilizada no início do século XX, época em que Vigotski escreveu seus textos. Seria equivalente hoje às expressões deficiência e educação especial. O autor dá destaque, em seus estudos, a caminhos alternativos, indiretos e a recursos especiais para o desenvolvimento e para a educação dessas crianças. Segundo Góes (2002), quando os caminhos naturais estão interrompidos, outros caminhos devem ser buscados, criados e priorizados. Tais caminhos indiretos de desenvolvimento são possibilitados pela cultura.

Vigotski (1997) também desenvolveu o conceito de compensação, cujo significado é possibilitar condições e estabelecer relações que permitam aos sujeitos com história de deficiência apropriar-se do conhecimento, independentemente de seu diagnóstico. "O desenvolvimento cultural seria, assim, a principal esfera em que é possível compensar a deficiência" (VIGOTSKI, 2011, p.863).

Seus estudos e suas pesquisas ocorreram, sobretudo, devido ao seu interesse em buscar melhorias nessa área. $\mathrm{O}$ autor teceu críticas à escola especial de seu tempo e tinha convicção de que deveria ser oferecida uma EE com condições diferenciadas, priorizando o desenvolvimento e a educação dos indivíduos. Por isso, por meio da educação, em qualquer momento histórico, a transmissão da cultura às futuras gerações deve ocorrer e possibilita compensar a deficiência.

Posto isso, a fim de aprofundarmos as nossas discussões e reflexões referentes à $E E$, inicialmente, o artigo traz uma discussão sobre a relevância do social e do aprendizado e desenvolvimento de acordo com a THC. Na sequência, são apresentadas as contribuições teóricas da THC para a educação especial na perspectiva inclusiva. Por fim, o artigo traz, de forma evidenciada, a importância das contribuições desta teoria para o contexto educacional inclusivo.

\section{A relevância do social e do aprendizado e desenvolvimento segundo a teoria histórico- cultural}

A transformação do homem só foi possível porque, no decorrer da história humana, os próprios homens e as suas condições de vida passaram por modificações e por aquisições que foram sendo transmitidas por gerações sucessivas. Ao se adaptarem à natureza, modificam-na, 
criam e alteram objetos para suprir suas necessidades e elaboram meios para a produção desses objetos, de instrumentos e de máquinas complexas. Como explica o próprio Leontiev (2004, p.283), os homens

Constroem habitações, produzem as suas roupas e os bens materiais. Os progressos realizados na produção de bens materiais são acompanhados pelo desenvolvimento da cultura dos homens; o seu conhecimento do mundo circundante deles mesmos enriquece-se, desenvolvem-se a ciência e a arte.

Apropriando-se das riquezas do mundo e participando do trabalho, do processo de produção e de outras formas de atividade social, desenvolvem-se as capacidades fundamentalmente humanas.

Ao nascer, o indivíduo requer mais do que a natureza lhe dispõe para poder viver; ele precisa apropriar-se do que foi produzido socialmente. Nesse processo, cada indivíduo aprende a ser homem. Marx, analisando a natureza social do homem, diz que

[...] Todas as suas [...] relações humanas com o mundo, a visão, a audição, o olfato, o gosto, o tato, o pensamento, a contemplação, o sentimento, a vontade, a atividade, o amor, em resumo, todos os órgãos da sua individualidade que, na sua forma, são imediatamente órgãos sociais, são no seu comportamento objetivo ou na sua relação com o objeto a apropriação deste, a apropriação da realidade humana (MARX apud LEONTIEV, 2004, p.286, grifo do autor).

Embora tenha-se passado mais de cento e cinquenta anos, essas ideias permanecem atuais; são expressão verídica da natureza das aptidões humanas, ou, como o próprio Marx afirma (MARX apud LEONTIEV, 2004, p.286), "das forças essenciais do homem”.

\begin{abstract}
Já vimos que a experiência sócio-histórica da Humanidade se acumula sob a forma de fenômeno do mundo exterior objetivo. Este mundo, o da indústria, das ciências e da arte é a expressão da história verdadeira da natureza humana; é o saldo da sua transformação histórica. Mas em que consiste o processo de apropriação deste mundo, que é ao mesmo tempo o processo de formação das faculdades específicas do homem? (LEONTIEV, 2004, p.286).
\end{abstract}

Para que os indivíduos se apropriem dos objetos e do fenômeno social, é necessária uma atividade que traga, em si, condições para que os traços fundamentais da atividade implícita no 
objeto se reproduzam. Em outras palavras, um instrumento é um objeto social, no qual estão incorporadas e fixadas as operações laborativas realizadas historicamente. Essas operações, cristalizadas nos objetos físicos, distinguem-se daquelas utilizadas por um animal.

Para o homem, adquirir um instrumento significa apropriar-se de operações motoras nele presentes. "É ao mesmo tempo um processo de formação ativa de aptidões novas, de funções superiores, 'psicomotoras', que 'hominizam' a sua esfera motriz" (LEONTIEV, 2004, p.287-288). Esses mesmos princípios aplicam-se à cultura intelectual. A aquisição da linguagem refere-se a uma forma de "[...] apropriação das operações de palavras que são fixadas historicamente nas suas significações [...]" (LEONTIEV, 2004, p.288). As apropriações implicam para o homem a criação de novas aptidões e funções psíquicas, o que difere fundamentalmente do processo de aprendizagem nos animais.

As aquisições do desenvolvimento histórico das aptidões humanas não são simplesmente dadas aos homens nos fenômenos objetivos da cultura material e espiritual que os encarnam, mas são aí apenas postas. Para se apropriar destes resultados, para fazer deles as suas aptidões, 'os órgãos da sua individualidade', a criança, o ser humano, deve entrar em relação com os fenômenos do mundo circundante através de outros homens, isto é, num processo de comunicação com eles. Assim, a criança aprende a atividade adequada. Pela sua função este processo é, portanto, um processo de educação (LEONTIEV, 2004, p.290, grifo do autor).

As afirmações do autor permitem-nos dizer que, no movimento da história, pela educação, acontece a transmissão da cultura às gerações futuras.

Até aqui, as reflexões levadas a termo mostram que o homem, ao vir ao mundo, está isento de defesas, mas, ao contrário dos demais animais, tem condições de desenvolver características essencialmente humanas. Revelam ainda que, no decorrer do desenvolvimento da humanidade, suas forças e suas aptidões são produtos de transformações sócio-históricas. No decorrer dos tempos, os homens alcançaram inúmeras conquistas, foram multiplicadas possibilidades físicas e intelectuais, foram produzidos conhecimentos sobre diferentes aspectos do universo; no entanto, o acesso a essas aquisições não é privilégio de todos. Há diferenças radicais referentes à riqueza da atividade material e à da riqueza mental no desenvolvimento das formas e das aptidões intelectuais. 
As distinções existentes entre os homens não são frutos de diferenças biológicas, mas sim produto da desigualdade econômica, da sociedade de classes. Sobre essa questão, os argumentos de Leontiev são elucidativos:

\begin{abstract}
A divisão social do trabalho tem igualmente como conseqüência que a atividade material e intelectual, o prazer e o trabalho, a produção e o consumo se separem e pertença a homens diferentes. Assim, enquanto globalmente a atividade do homem se enriquece e se diversifica, a de cada indivíduo tomado à parte estreita-se e empobrece. Esta limitação, este empobrecimento podem tornar-se extremos, sabemo-lo bem, quando um operário, gasta todas as suas forças para realizar uma operação que tem de repetir milhares de vezes (LEONTIEV, 2004, p.294, grifo do autor).
\end{abstract}

Além das riquezas materiais, a classe dominante acaba concentrando também a produção intelectual. Não se pode esquecer que, aos povos de todas as nações, é preciso garantir o desenvolvimento físico e psíquico. Para que isso ocorra, é necessário que os homens se libertem da necessidade material e superem a divisão entre trabalho intelectual e trabalho físico.

A história dos homens mostra que a diferentes modos de produzir a vida material correspondem distintos valores, conceitos, formas de pensar, enfim, modos próprios de ser e, por conseguinte, de uma determinada educação. Os valores mais amplos consolidam-se nos objetivos postos para a educação e para o ensino, tendo em vista uma formação que busca satisfazer às necessidades historicamente estabelecidas. Sabe-se, ainda, que os indivíduos se apropriam desses valores e desses conhecimentos disponíveis na cultura por meio de relações estabelecidas no decorrer de suas vidas; é na relação com outros homens que cada um se individualiza. Dessa forma, no contexto escolar, é importante que o professor compreenda o processo de desenvolvimento do psiquismo humano para que possa fazer uma mediação que contribua com esse desenvolvimento.

Luria (2001) ressalta que, ao nascer, a criança está inserida em uma determinada sociedade e traz consigo aspectos anatômicos e fisiológicos, oriundos da história de seus antepassados. A apropriação da cultura é necessária para que o homem adquira cultura própria. Vigotski (2001) considera a inserção da criança na cultura, a interação com as demais crianças e pessoas, por meio de trocas, condições indispensáveis para seu aprendizado e seu desenvolvimento. Na efetivação desses processos, ocorre a internalização de signos e de significados culturais. 
A consciência nunca foi um 'estado interior' primário da matéria viva; os processos psicológicos surgem não no 'interior' da célula viva, mas em suas relações com o meio circundante, na fronteira entre o organismo e o mundo exterior, e ela assume as formas de um reflexo ativo do mundo exterior, que caracteriza toda atividade vital do organismo (LURIA, 1998, p.97).

Vigotski (2001) considera os instrumentos e os signos mediadores culturais, cuja origem encontra-se na história da humanidade, resultados decorrentes da relação entre pessoas e grupos. Os instrumentos são utilizados pelo homem na realização de seu trabalho e fazem a intermediação entre o homem e o seu objeto de trabalho. O autor explica que, como os signos são a representação da realidade, tornam-se auxiliares internos, que têm a função de mediar as atividades psicológicas, caracterizando-se como instrumentos não materiais. Dentre os signos, a linguagem é o sistema simbólico mais complexo criado pelos homens devido à sua necessidade de comunicação.

Sobre o ensino e o desenvolvimento mental da criança na idade escolar, Vigotski (2001) explica que o nível de desenvolvimento em que a criança se encontra constitui-se como ponto de partida quando tentamos esclarecer as relações reais entre o processo de desenvolvimento e as possibilidades da aprendizagem da criança. São dois os níveis de desenvolvimento: o primeiro é denominado, pelo autor, nível de desenvolvimento real, que corresponde ao nível de desenvolvimento em que a criança se encontra; o outro nível é a zona de desenvolvimento imediato e corresponde ao que a criança revela poder realizar com a ajuda do outro.

O que hoje a criança faz com auxílio do adulto fará amanhã por conta própria. A zona de desenvolvimento imediato pode determinar para nós o amanhã da criança, o estado dinâmico do seu desenvolvimento que leva em conta não só o já atingido mas também o que se encontra em processo de amadurecimento. [...] O estado de desenvolvimento mental da criança pode ser determinado pelo menos através da elucidação de dois níveis: do nível de desenvolvimento atual e da zona de desenvolvimento imediato (VIGOTSKI, 2001, p.480).

Sobre os processos de desenvolvimento e de aprendizagem, as linhas da aprendizagem escolar provocam processos interiores de desenvolvimento. Os processos de desenvolvimento não coincidem com os processos de aprendizagem, ou seja, os primeiros seguem os segundos que, por sua vez, criam zonas de desenvolvimento imediato. Muda-se, dessa forma, a concepção 
tradicional sobre desenvolvimento e aprendizagem: enquanto na concepção anterior o domínio de alguma operação significava a conclusão dos processos de desenvolvimento, nessa nova forma de pensar, esses processos têm início nesse momento.

Outra questão importante é o entendimento de que, embora aprendizagem e desenvolvimento da criança estejam relacionados, eles não caminham de forma paralela. 0 desenvolvimento da criança progride mais lentamente e atrás do processo de aprendizagem, como se fosse uma sombra dela. Fundamentando-se nessa premissa, podemos concluir que os testes escolares nunca representam a visão real do desenvolvimento da criança. "Em realidade, entre os processos de desenvolvimento e aprendizagem se estabelecem dependências dinâmicas as mais complexas, que não podem ser abrangidas por uma forma especulativa única e a priori" (VIGOTSKI, 2001, p.487, grifo do autor).

Cada objeto tem uma relação concreta original voltada ao desenvolvimento da criança, relações que se modificam nela quando passa de um nível a outro. Partindo-se desse princípio, no processo educacional, não há como utilizar fórmulas mágicas para promover aprendizagem ao aluno, mas, aqui, abrem-se possibilidades para investigações mais amplas e diversificadas a respeito de como o ensino deva atuar, por meio da mediação pedagógica para proporcionar aprendizagem e desenvolvimento da criança em idade escolar, tenha a criança deficiência ou não.

A formação social da mente pensante sobre o real não se forma unicamente com o olhar sobre si, sobre a sua deficiência ou para o coletivo das pessoas com deficiência. Requer, primeiramente, o entendimento sobre o porquê de elas assumirem certos posicionamentos e desempenharem determinados papéis sociais. Posicionamo-nos a favor de que as pessoas com deficiência convivam com as sem deficiência. Defendemos a boa escola para todos com a valorização da história, da filosofia e da psicologia, pois se espera a contribuição dos subsídios que ultrapassem os limites biológicos para se pensar a aprendizagem e o desenvolvimento.

\section{Contribuições da teoria histórico-cultural para a educação especial na perspectiva inclusiva}

Mesmo que nosso contexto sócio-histórico seja muito diferente do vivenciado por Vigotski (1997), acreditamos que retomar seus escritos possibilita afirmar a sua importância e, 
certamente, oferecer contribuições para a formação e a atuação de professores e de psicólogos.

Kozulin (1994) lembra que a produção de Vygotsky foi orientada tanto para questões teóricas quanto para o atendimento a demandas práticas. Na década de 1920, depois do período que abrangeu a primeira Guerra Mundial, a Revolução Russa e a Guerra Civil, era imenso o número de crianças e jovens abandonados, órfãos ou desligados da família, que apresentavam doenças decorrentes de desnutrição, deficiências, distúrbios emocionais, transtornos de conduta ou envolvimento em delinqüência e prostituição (GÓES, 2002, p.97).

Vigotski (1997) explica que a defectologia é considerada uma pedagogia menor, sob a perspectiva tradicional, pois se baseava em uma concepção quantitativa do desenvolvimento infantil. Na defectologia moderna, o enfoque quantitativo é criticado em sua tese básica, já que a criança prejudicada por um defeito não é considerada menos desenvolvida que as crianças ditas normais, mas desenvolve-se de outra maneira. A criança com deficiência apresenta um desenvolvimento distinto, diferenciado das demais.

O desenvolvimento da criança com deficiência é, ao mesmo tempo, igual e diferente ao da criança normal. As leis de desenvolvimento são as mesmas, assim como as metas educacionais. Por outro lado, para se desenvolver e se educar, ela precisa de certas condições peculiares. É um entrelaçamento conceitual complexo de igualdade-diferença, mas, 'precisamente para que a criança com deficiência possa alcançar o mesmo que a criança normal, devemse utilizar meios absolutamente especiais' (1929: 24). Logo, caminhos alternativos e recursos especiais não são peças conceituais secundárias na compreensão desse desenvolvimento. [...] As vias alternativas e especiais dependem de uma série de condições, inclusive de outros espaços da cultura e mudanças de mentalidade do grupo social. Por isso, os membros 'normais' das comunidades devem ser reeducados no sentido de contribuir para a formação da pessoa com deficiência (GÓES, 2002, p.105-106).

Barroco (2012) realizou estudos sobre a teoria vigotskiana e a defectologia, especialmente sobre os estudos desenvolvidos por Vigotski entre as décadas de 1920 e de 1930, em que ele se dedicou à educação de pessoas com deficiência. Seus estudos demonstram que

A Defectologia é um termo empregado por autores soviéticos e pelo próprio L. S. Vygotski (1896-1934), no início e ao longo do século XX. Diz respeito a uma área que congrega estudos teórico-metodológicos relativos a intervenções educacionais, similar ao que, hoje, denominamos de Educação Especial. 
Abordar a Nova Defectologia e a Psicologia Soviética propostas por Vygotski e seus colaboradores e continuadores se deve ao fato de educadores e demais profissionais envolvidos terem formulado teorias e desenvolvido intervenções que nos parecem relevantes para a educação do século XXI (BARROCO, 2012, p.41).

Para Barroco (2012), a compreensão da teoria vigotskiana é fundamental, pois o autor bielorrusso, que tinha a sua bandeira de luta voltada, em especial, à educação de pessoas com deficiência, deu importância significativa às relações sociais e às interações entre os homens. Os pensamentos de vários educadores soviéticos caminharam na vertente de um modelo de educação que contribuísse para a formação do que denominavam de 'novo' homem da contemporaneidade na Rússia e na posterior União Soviética, campo de aplicação do marxismo. A sociedade pós-capitalista desejava a formação desse novo homem, livre e não alienado. Utilizamos as indagações de Barroco (2012) para responder às nossas inquietações sobre educação e Educação Especial Inclusiva. Dentre elas: qual é a repercussão desta educação na obra de Vigotski e na Nova Defectologia? Qual é a importância desta educação para a compreensão de coletividade na Educação Especial ou Inclusiva na contemporaneidade?

Segundo Barroco (2012), Marx e Engels consideram os problemas da humanidade como contradições sociais reais, uma vez que as ideias são produzidas e ventiladas como verdades absolutas. Tais contradições não resolvidas são projetadas como formas ideológicas de consciência, em soluções que as camuflam. "Por este modo, o mundo das aparências não só gera formas econômicas de ideologia, mas é um paraíso dos direitos onde reinam a liberdade, a igualdade, a propriedade" (Barroco, 2012, p.54). A autora ressalta que a sociedade burguesa pode assumir dois sentidos distintos: ser utilizada como um processo de adaptação junto às relações sociais ou ser empregada como arma de luta contra a opressão, transformando-se em instrumento moral e intelectual do novo homem.

Para Vigotski (1997), o processo de desenvolvimento da criança com deficiência depende socialmente de dois aspectos: da realização social e do defeito e da orientação social dada à compensação no processo das condições criadas no meio em que a criança está inserida. Compensação não significa que um dos sentidos tem maior propriedade devido ao déficit em outro, mas, devido ao déficit em um dos órgãos e com uma mediação adequada, podemos estimular bastante um dos órgãos, conseguindo o desenvolvimento de potencialidades. Assim, 
a criança com "defeito" não é considerada uma criança com deficiência; o que diferenciará o seu grau de comprometimento intelectual, o seu déficit cognitivo e a sua normalidade, no final da formação de toda sua personalidade, será a compensação social que a pessoa teve.

Sobre a contribuição do social na formação do psiquismo humano e na nova defectologia, o aprisionamento biológico da psicologia é rompido e cede espaço à psicologia histórica, humana. A palavra social ganha o significado de que tudo que é cultural é social. A cultura é considerada o resultado da vida em sociedade, construída por meio da atividade social do homem. O signo, por estar localizado fora do organismo, semelhante ao instrumento, encontra-se isolado do homem; em sua essência, é um órgão da sociedade. Nessa perspectiva, a origem das funções complexas do pensamento não é encontrada na biologia, nem na história pura da filogênese, mas sim no social. "Poderíamos indicar o resultado fundamental a que nos conduz a história do desenvolvimento cultural da criança como a sociogênese das formas superiores de comportamento" (VIGOTSKI, 2011, p.864). Segundo Vigotski (1997), a história do desenvolvimento cultural da criança deficiente aparece como um dos problemas mais intensos da defectologia atual. Segundo investigação científica, ele evidenciou que ela desempenha um novo plano no processo de desenvolvimento.

A mediação social e pedagógica exerce papel primordial no desenvolvimento das funções intelectivas do psiquismo humano, que não é estático nem deve ser entendido considerando somente a condição biológica.

Para o autor, o desenvolvimento de uma criança sem deficiência no processo civilizatório ocorre por meio da ligação dos planos de desenvolvimento natural e cultural, ambos se coincidem e funcionam mutuamente. A fusão dos planos pode ser exemplificada pelo desenvolvimento da linguagem. Referente à criança com deficiência, essa fusão não é observada, pois os dois planos divergem entre si, de forma marcante, devido ao defeito orgânico. No sistema civilizatório, as ferramentas e os materiais de adaptação estão programados para a criança "normal". Com frequência, a criança com deficiência necessita de formas culturais diferenciadas das utilizadas com as crianças sem deficiência; são exemplos o alfabeto táctil criado para o cego, a dactologia e a mímica gestual dos "surdos". "Os processos de domínio e utilização destes sistemas culturais auxiliares se distinguem por sua profunda peculiaridade em comparação com 
o uso dos meios habituais da cultura" (VIGOTSKI, 1997, p.28, tradução nossa) ${ }^{3}$.

Essas adaptações denominadas de instrumentos psicológicos são orientadas para o domínio dos processos da conduta. Consideram a atenção involuntária como natural e a voluntária como artificial. As ferramentas psicológicas podem modificar todo o curso do desenvolvimento das funções psicológicas (memória, atenção). A criança com deficiência é incapaz de usar as funções psicológicas naturais sem medidas específicas e, por sua vez, dominar as ferramentas psicológicas, que são essenciais para o desenvolvimento humano.

Desse modo, Vigotski (2011) afirma que, para se apropriar dos conhecimentos produzidos pela humanidade, é necessário que as estruturas das formas complexas de pensamento da criança versem em uma forma de caminhos indiretos, que atuam quando a operação psicológica da criança é impossibilitada de atuar pelas vias diretas.

Porém, uma vez que esses caminhos indiretos são adquiridos pela humanidade no desenvolvimento cultural, histórico, e uma vez que o meio social, desde o início, oferece à criança uma série de caminhos indiretos, então, muito frequentemente, não percebemos que o desenvolvimento acontece por esse caminho indireto (VIGOTSKI, 2011, p.864).

Quando realiza uma tarefa, o objetivo fundamental não é atingido de forma direta, mas é deixado para o final. O intervalo é preenchido por uma série de operações, que tem como intuito a resolução de problemas por um caminho indireto. Vigotski (2011, p.864-865) explica:

[...] a criança começa a contar nos dedos quando, por não estar em condições de dar uma resposta direta à pergunta do professor sobre o resultado de 6 mais 2 , ela conta nos dedos 6 , depois 2 e diz: 8 . Aqui temos novamente a estrutura do caminho indireto para a realização de determinada operação - uma conta: a criança, sem ter uma resposta pronta automática, utiliza as próprias mãos, que antes eram para ela somente pano de fundo. Nesse caso, as mãos, que não possuem relação direta com a pergunta, adquirem significado de instrumento assim que a execução da tarefa pelo caminho direto se mostra impedida para a criança. [...] A estrutura do caminho indireto surge apenas quando aparece um obstáculo ao caminho direto, quando a resposta pelo caminho direto está impedida; em outras palavras, quando a situação apresenta exigências tais, que a resposta primitiva revela-se insatisfatória.

\footnotetext{
3 "Los procesos de dominio y utilización de estos sistemas culturales auxiliares se distinguen por su profunda peculiaridad en comparación con el uso de los medios habituales de la cultura".
} 
A tese central do autor é a de que caminhos indiretos e alternativos podem ser possibilitados, criados pela cultura quando o caminho direto está impossibilitado. "O desenvolvimento cultural seria, assim, a principal esfera em que é possível compensar a deficiência" (VIGOTSKI, 2011, p.863).

Outro aspecto fundamental a ser considerado, segundo o autor, é que o desenvolvimento das formas superiores de comportamento ocorre em razão das necessidades, ou seja, temos de organizar as dificuldades que obrigam a criança a pensar para corrigir seu comportamento ao buscar possibilidades para resolvê-las, levando-a a pensar antes de agir. $\mathrm{Na}$ antiguidade, os psicólogos estudavam o processo de desenvolvimento cultural e seu processo de educação de forma unilateral. Atualmente, a compreensão ocorre de forma diferenciada. Ao inserir-se na cultura, a criança se apropria dos conhecimentos produzidos pela humanidade. Por sua vez, essa cultura reelabora o comportamento da criança, refazendo, de forma diferenciada, todo o curso de seu desenvolvimento.

A diferenciação do plano dos desenvolvimentos natural e cultural dá início a uma nova teoria educacional. Pela primeira vez, a concepção dialética sobre o desenvolvimento da criança é introduzida. Agora não mais com a ingênua visão de que o desenvolvimento cultural é a continuação direta do natural. As novas pesquisas demonstram aspectos diferenciados no desenvolvimento e não o concebem mais como um movimento em linha reta. Antigamente, a educação ensinava a criança a dar pequenos e tranquilos passos rumo ao desenvolvimento. Nos dias atuais, a teoria deve ensiná-la a saltar.

A transformação do material natural em uma forma histórica é sempre um processo não de simples mudança orgânica, mas de complexa mudança do próprio tipo de desenvolvimento. Assim, a principal conclusão que pode ser tirada da história do desenvolvimento cultural da criança, em relação à sua educação, é a seguinte: à educação cumpre sempre enfrentar uma subida onde antes se via um caminho plano; ela deve dar um salto onde até então parecia ser possível limitar-se a um passo. O primeiro mérito da nova pesquisa consiste exatamente em ter revelado um quadro complexo onde antes se via um simples. Mas esse ponto de vista produz uma verdadeira revolução nos princípios da educação quando nos aproximamos da educação da criança anormal (VIGOTSKI, 2011, p.867).

Ficou claro que existem diferenças essenciais quando tratamos da educação da criança 
"anormal", como dizia Vigotski (2011). A nossa cultura está programada para as pessoas que possuem seus órgãos e suas funções cerebrais em perfeito estado, tais como as mãos, os olhos, os ouvidos. Os signos e os símbolos representam um tipo normal de pessoa. Por isso, existe a expectativa da passagem natural às culturas de aprendizagem pelos mesmos canais sensoriais e da mesma forma para todos os seres humanos. Ao nos depararmos com pessoas, com educandos com deficiência na organização psicofisiológica, na leitura de um leigo, a convergência é substituída pela divergência, uma diferença significativa entre os aspectos natural e cultural no processo de desenvolvimento da criança. Deixada ao desenvolvimento natural, sem uma mediação social ou pedagógica, uma criança desprovida de visão não aprenderá a escrever e outra surda não conseguirá falar. A educação, portanto, possibilita que ocorra a adaptação necessária às especificidades psicofisiológicas do educando com deficiência, por meio de caminhos alternativos, com técnicas criadas e de um sistema especial de signos e de símbolos culturais.

Dessa forma, Vigotski (2011) exemplifica que, para os cegos, a escrita visual é realizada por meio do Braille, uma forma tátil, que permite a composição do alfabeto combinando pontos em relevo. A leitura é realizada quando se tocam os pontos na página e a escrita acontece quando se perfura o papel, marcando-o com os pontos em relevo. Por sua vez, para os surdos, um caminho indireto é realizado, já que o alfabeto manual é construído como caminho alternativo. Agora são criados signos visuais, nos quais são realizadas diversas posições das mãos. Nesse caso, a criança surda faz a leitura pelo canal sensorial visual.

\begin{abstract}
Esses caminhos alternativos especialmente construídos para o desenvolvimento cultural da criança cega e da surda-muda, a língua escrita e falada especialmente criada para elas são extremamente importantes na história do desenvolvimento cultural em dois aspectos. Os cegos e os surdosmudos são como um experimento natural que demonstra que o desenvolvimento cultural do comportamento não se relaciona, necessariamente, com essa ou aquela função orgânica. A fala não está obrigatoriamente ligada ao aparelho fonador; ela pode ser realizada em outro sistema de signos, assim como a escrita pode ser transferida do caminho visual para o tátil (VIGOTSKI, 2011, p.868).
\end{abstract}

É fundamental também a compreensão da formação do psiquismo humano em pessoas com deficiência. Para isso, buscamos explicações em Barroco (2012), que ressalta a necessidade de avaliar como o homem se constitui como tal. Essa análise parte do princípio de que, em sua 
formação, a diferença não se concentra basicamente na deficiência, mas na essência da formação do que é realmente humano. O trabalho é tido como peça fundamental dos afazeres educativos. Leontiev (2004) e Barroco (2012) destacam a importância da cultura no processo de humanização do indivíduo.

Desde o nascimento, ele mantém uma relação de pertença à espécie humana mediada primariamente por aquilo que a genética lhe oportuniza. A partir dessa base biológica, é estabelecido o desenrolar de um longo processo de apropriação das características humanas historicamente formadas, que são próprias ao gênero humano (BARROCO, 2012, p.46).

O trabalho é entendido como uma atividade consciente que garante, em primeiro plano, o contato do homem com a natureza. Essa possibilidade de relação eleva o homem da condição de ser simplesmente espécie, pautado na herança biológica. A consciência, o que diferencia os homens dos animais, é formada durante extensa relação com o mundo do trabalho. As práticas sociais possibilitam ao indivíduo a apropriação do que já foi elaborado pelo homem, possibilitando-Ihe apropriar-se de sua objetivação. Torna-o em condições de ser identificado como exemplo do gênero humano ou não. Por outro lado, a mesma prática social pode levá-lo a uma prática social alienante e alienada. "Ela pode mascarar o real e a sua constituição ao retirar a potencialidade que a história, sendo disciplina e conteúdo, tem para o desvendamento da formação social da mente humanizada" (BARROCO, 2012, p.47).

Consideramos esta exposição fundamental para a EE ou Educação Inclusiva, haja vista a necessidade de debater sobre o fatalismo e o determinismo biológico como fundantes na formação do psiquismo humano e apontados como responsáveis pelo não desenvolvimento da pessoa com deficiência. Ao entendermos a formação social da mente ou do psiquismo humano como fruto da relação dos homens com o mundo, fica evidenciado, de acordo com a teoria vigotskiana, que o homem é considerado como criador e criativo. Isento, porém, de uma prática social estabelecida, as possíveis apropriações, por ela proporcionadas, podem ser apresentadas ao homem de maneira alienada, embotada, de forma reprodutiva e não criativa.

Segundo o pensamento marxista, que dá base à psicologia soviética, a atividade vital, o trabalho, diz respeito a um processo que o homem estabelece com a 
natureza. Por ela, buscando suprir suas necessidades, o homem medeia, regula e controla o seu próprio comportamento e metabolismo. Ao dominar a natureza, ele acaba pondo em movimento as forças dos seus braços e pernas, cabeça e mãos e, assim, pode apropriar-se da matéria natural de uma forma útil, modificando a natureza externa e a sua própria natureza. Ou ainda, por ela, o homem altera sua constituição biológica e cria e usa ferramentas, potencializa a ação do seu corpo e transforma os órgãos biológicos em sociais (BARROCO, 2012, p.49).

O trabalho é responsável por estabelecer ligações entre os homens, realizar fins, sejam individuais ou coletivos, desenvolvendo-os ou os regulando. O trabalho é condição primordial para a humanização do homem, com ou sem deficiência.

\section{Considerações finais}

Após estudos referentes à THC e aos aportes da EE na perspectiva inclusiva, pudemos constatar as significativas contribuições dessa teoria para a educação de pessoas com deficiência. Referente à aprendizagem, ao desenvolvimento e às demais questões levantadas nesse estudo, acreditamos, de fato, que esta teoria nos oferece subsídios e recursos que nos permitem refletir por meio de seus pressupostos e buscar encaminhamentos nos contextos social e escolar que contribuam para que o homem passe do estado de hominização ao estado de humanização independentemente de comprometimentos orgânicos. O desenvolvimento de suas potencialidades não é refém de suas características biológicas.

O nível de desenvolvimento em que a criança se encontra na idade escolar, segundo Vigotski (2001), constitui-se como ponto de partida para o processo de desenvolvimento e as possibilidades da aprendizagem da criança.

Os estudos de Vigotski (1997) e suas pesquisas ocorreram, em especial, devido ao seu interesse em buscar melhorias nessa área. Teceu críticas à escola especial de seu tempo e teve convicção de que deveria ser oferecida uma EE em condições diferenciadas, primando pelo desenvolvimento e pela educação. A tese básica da defectologia atual é a de que todo defeito cria estímulos para elaborar uma compensação, sendo assim, é necessário criar substitutivos, caminhos alternativos no desenvolvimento da conduta infantil, quando os caminhos naturais estão interrompidos. Após muitos anos de sua morte, sua teoria é tão atual e nos demonstra 
imensas possibilidades no trabalho nessa modalidade de ensino no contexto escolar.

Como explicitou Vigotski (2011), as leis do desenvolvimento são as mesmas para todos os educandos, porém, para se desenvolverem e se educarem, condições diferentes são imprescindíveis. $\mathrm{O}$ acesso e a permanência na escola devem ser possibilitados a todos, já que a aprendizagem e o desenvolvimento devem ultrapassar os limites da natureza biológica. Nessa perspectiva teórica, o social é fundamental na formação do psiquismo humano e na nova defectologia; dessa maneira, a psicologia rompe com o aprisionamento biológico e cede espaço a uma psicologia histórica e humana.

Somos a favor da convivência das crianças com seus pares no contexto escolar inclusivo. Acreditamos em políticas públicas inclusivas que, ao se efetivarem realmente, promovam mudanças, que não fiquem apenas no acolhimento, no conviver juntos, mas que possibilitem às escolas condições para desempenharem a sua função, ou seja, promover o conhecimento e elevar o homem à condição humana.

Para se apropriar dos conhecimentos produzidos pela humanidade, é necessário que as estruturas das formas complexas de pensamento da criança com deficiência versem em caminhos indiretos e alternativos, que atuam quando a operação psicológica da criança é impossibilitada de atuar pelas vias diretas. Cabe à escola, por meio do professor, realizar mediações pedagógicas que possibilitem e oportunizem a apropriação de signos e de símbolos que expressam o conhecimento acumulado e que estão presentes em nossa cultura. Estão fora do organismo e devem ser disponibilizados para o desenvolvimento das funções psicológicas superiores de todos os alunos, com ou sem deficiência. Caso o aluno possua uma deficiência, na maioria das vezes, os caminhos devem ser diferenciados, pois, por vias naturais, esta apropriação não é possível.

Os estudos da THC sobre a defectologia nos possibilitam a compreensão da importância da mediação do professor e o papel da escola no desenvolvimento de potencialidades do aluno, em especial na educação inclusiva. A convivência com seus pares, com ou sem deficiência, faz toda a diferença neste processo e contribuem ao processo de humanização de todos, no contexto escolar. O sistema educacional inclusivo, por meio de caminhos alternativos criados pela cultura, considerando a deficiência, a necessidade de acessibilidade pedagógica e arquitetônica que o educando com deficiência possui, pode proporcionar a ele condições de 
desenvolvimento e de aprendizagem, conforme discutimos ao longo deste texto. Trouxe-nos uma visão diferenciada referente às possibilidades de trabalho com o público-alvo da EE.

\section{Referências}

BARROCO, S. M. S. Contexto e textos de Vygotski sobre a defectologia: a defesa da humanização da pessoa com deficiência. In: BARROCO, S. M. S.; LEONARDO, N. S. T.; SILVA, T. S. A. (orgs.). Educação especial e teoria histórico-cultural: em defesa da humanização do homem. Maringá: EDUEM, 2012. p.41-65.

GÓES, M. C. R. G. Relações entre desenvolvimento humano, deficiência e educação: contribuições da abordagem histórico-cultural. In: OLIVEIRA. M. K.; SOUZA, D. T.; REGO, T. C. (orgs.). Psicologia, educação e as temáticas da vida contemporânea. São Paulo: Moderna, 2002. p.95-114.

LEONTIEV, A. O desenvolvimento do psiquismo. 2. ed. São Paulo: Moraes, 2004.

LURIA, A. R. O cérebro humano e a atividade consciente. In: VIGOTSKI, L. S.; LURIA, A. R.; LEONTIEV, A. N. Linguagem, desenvolvimento e aprendizagem. São Paulo: ícone, 1998. p.191228.

LURIA, A. R. Pensamento e linguagem: as últimas conferências de Luria. 2. ed. Porto Alegre: Artmed, 2001.

VIGOTSKI, L. S. Obras escogidas: tomo V. Madrid: Visor, 1997.

VIGOTSKI, L. S. Psicologia pedagógica. São Paulo: Martins Fontes, 2001.

VIGOTSKI, L. S. A defectologia e o estudo do desenvolvimento e da educação da criança anormal. Revista Educação e Pesquisa, São Paulo, v.37, n.4, p.861-870, dez. 2011. Disponível em: http://www.scielo.brscielo.phppid=S1517-97-97022011000400012\&script=sci_arttext. Acesso em: 01 fev.2013.

Recebido em maio 2020.

Aprovado em janeiro 2021. 